\title{
Measuring the Efficiency of a Hospital based on the Econometric Stochastic Frontier Analysis (SFA) Method
}

Satar Rezaei ${ }^{1}$, Hamed Zandian², Akram Baniasadi ${ }^{3}$, Telma Zahirian Moghadam ${ }^{4}$, Somayeh Delavari ${ }^{5}$, Sajad Delavari $^{6}$

${ }^{1}$ Research Center for Environmental Determinants of Health, Kermanshah University of Medical Sciences, Kermanshah, Iran

${ }^{2}$ Department of Public Health, School of Health, Ardabil University of Medical Sciences, Ardabil, Iran

${ }^{3}$ Department of Health Management and Economics, School of Public Health, Tehran University of Medical Sciences, Tehran, Iran

${ }^{4}$ Health Management and Economics Research Center, Iran University of Medical Sciences, Tehran, Iran

${ }^{5}$ Department of Medical Education, School of Medicine And Center for Educational Research in Medical Sciences (CERMS), Iran University of Medical Sciences, Tehran, Iran

${ }^{6}$ Health Human Resources Research Center, School of Management and Information Sciences, Shiraz University of Medical Sciences, Shiraz, Iran

\section{Type of article: Original}

\begin{abstract}
Introduction: Hospitals are the most expensive health services provider in the world. Therefore, the evaluation of their performance can be used to reduce costs. The aim of this study was to determine the efficiency of the hospitals at the Kurdistan University of Medical Sciences using stochastic frontier analysis (SFA).

Methods: This was a cross-sectional and retrospective study that assessed the performance of Kurdistan teaching hospitals $(n=12)$ between 2007 and 2013. The Stochastic Frontier Analysis method was used to achieve this aim. The numbers of active beds, nurses, physicians, and other staff members were considered as input variables, while the inpatient admission was considered as the output. The data were analyzed using Frontier 4.1 software.

Results: The mean technical efficiency of the hospitals we studied was 0.67 . The results of the Cobb-Douglas production function showed that the maximum elasticity was related to the active beds and the elasticity of nurses was negative. Also, the return to scale was increasing.

Conclusion: The results of this study indicated that the performances of the hospitals were not appropriate in terms of technical efficiency. In addition, there was a capacity enhancement of the output of the hospitals, compared with the most efficient hospitals studied, of about $33 \%$. It is suggested that the effect of various factors, such as the quality of health care and the patients' satisfaction, be considered in the future studies to assess hospitals' performances.
\end{abstract}

Keywords: technical efficiency, stochastic frontier analysis, hospital

\section{Introduction}

In recent decades, health system expenditures, especially hospitals, have increased throughout the world. The hospitals' share of the total cost of the health system varies between 50 and $80 \%$ in developed and developing countries. The main factors, such as aging, new and expensive technology, the increasing expectation and knowledge of people about their health status, and inefficient use of resources in hospitals can be affecting the increase in healthcare costs (1-2). One of ways to decrease healthcare costs, especially in hospitals, is to assess their performance over time by measuring their productivity and efficiency $(2,3)$. Measuring the performance of hospitals due to the numbers of input and outputs is very difficult and complicated (4). There are two methods for evaluating the

\section{Corresponding author:}

Sajad Delavari. Health Human Resources Research Center, School Of Management and Information Sciences, Shiraz University of Medical Sciences, Shiraz, Iran, E-mail: sajadd@gmail.com, Tel: +98.7132340774

Received: September 10, 2015, Accepted: December 28, 2015, Published: February 2016

iThenticate screening: November 17, 2015, English editing: February 08, 2016, Quality control: February 10, 2016 (C) 2016 The Authors. This is an open access article under the terms of the Creative Commons Attribution-NonCommercialNoDerivs License, which permits use and distribution in any medium, provided the original work is properly cited, the use is noncommercial and no modifications or adaptations are made. 
performance of hospitals and other healthcare providers, i.e., data envelopment analysis (DEA) and stochastic frontier analysis (SFA).

DEA, as a non-parametric technique, is based on linear programming that estimates the frontier production function. This function is the maximum possible product that comes from a certain number of inputs. The shapes of the functions are convex, and there are no points under them (5). SFA, as a parametric technique, is based on econometric models and the theories of microeconomics. The technique uses a combination of data (panel data) to estimate the production (cost) function with regard to the hypothesis or statistical tests. SFA has several advantages over DEA. In the DEA approach, the efficiency of hospitals is measured relative to the observed best practice among all of the hospitals, and it does not provide any statistical test to confirm the results. However, in the SFA technique, the efficiencies of the hospitals are estimated and ranked based on the production (cost) function. Also, the DEA technique considers only one output, while SFA considers more than one output since hospitals have many important outputs (6). Previous studies have used the DEA and SFA techniques to determine technical efficiency of hospitals in developed and developing countries (Zere et al. in South Africa in 2000; Rosko in the USA in 2001; Goudarzi et al. in Iran in 2013; and Sajadi et al. in Iran in 2009 (4, 7-9). The aim of the current study was to use the SFA technique to determine the technical efficiency of teaching hospitals affiliated with the Kurdistan University of Medical Sciences in Iran from 2007 to 2013.

\section{Material and Methods}

This was a cross-sectional and retrospective study that estimated the technical efficiency of 12 teaching hospitals affiliated with Kurdistan University of Medical Sciences over 7 years from 2007 to 2013. The SFA method was used to reach this aim. Based on a previous study (4), four inputs, including the number of active beds, number of physicians (general and specialist), number of nursing staff, and the number of other staff members (non-medical staff and medical staff except nursing and physicians) and one output including the number of inpatient admissions were included in the study. The Cobb-Douglas function was used in the following formula (equation 1):

$\operatorname{Ln} Y_{i t}=\beta_{0}+\sum B_{j} X_{j i t}+\left(V_{i}-U_{i}\right)$

Where:

Ln: natural logarithm

$\mathrm{Y}_{\mathrm{it}}$ : output for hospital $\mathrm{i}$ in time $\mathrm{t}$

$\mathrm{X}_{\mathrm{it}}$ : a vector of inputs for hospital $\mathrm{i}$ in time $\mathrm{t}$

$\mathrm{U}_{\mathrm{it}}$ : hospital-specific fixed effects

$\mathrm{V}_{\mathrm{it}}$ : random error term

Also, we used the likelihood Ratio (LR) to select the proper model (equation 2).

$L R=-2 \quad L \quad H_{0}-\operatorname{Ln}\left[L\left(H_{1}\right)\right]$

Where $\mathrm{L}\left(\mathrm{H}_{0}\right)$ is the null hypothesis likelihood function, and $\mathrm{L}\left(\mathrm{H}_{1}\right)$ is the hypothesis, which is asymptotically presupposed to have a mixed chi-squared distribution (10). Frontier 4.1 software was used to analyze the data.

\section{Results}

The average of number of nursing staff, physicians and other staff for all hospitals over the study periods (2007-2013) were 127,38 , and 155 , respectively. Also, the average number of active beds and number of inpatients admission were 138 and 11,046, respectively (Table 1). Estimated results by stochastic Frontier Analysis are presented in Table 2 . The results showed that the LR test was equal to 15.7, indicating that the Cobb-Douglas function form was more appropriate. The results of the estimated elasticity of the input variables are presented in Table 3 . Our findings indicated that the elasticity of active beds was 0.87 , which was higher than the elasticities of other variables. Conversely, this finding showed that there were $10 \%$ increases in active beds, and the number of inpatient admissions increased by $8.7 \%$. Also, the sum of elasticity of all variables was equal to 1.21 ; this finding showed that the return to scale was increasing. The elasticity of inputs of production and types of return to scale are shown in Table 3 . The mean of technical efficiency of the hospitals over the period of the study was 0.68 based on the SFA model. The technical efficiency for studied hospital and their ranking between 2007 and 2013 by the SFA model are shown in Table 4. Also, our findings indicated that the highest and lowest technical efficiency among the hospitals were associated with Sina hospital at Kamyaran (0.91) and Shohada hospital at Dehgolan (0.36), respectively. Over the study period, the mean score of technical efficiency increased from 0.63 in 2007 to 0.75 in 2013. 
Table 1. Descriptive statistics of inputs and output variables for the hospitals (2007-2013)

\begin{tabular}{|l|l|l|l|l|l|}
\hline Hospitals & Active beds & Physicians & Nursing staff & Other staff & Inpatients \\
\hline A & 362 & 110 & 339 & 378 & 31500 \\
\hline B & 342 & 75 & 305 & 290 & 18321 \\
\hline C & 177 & 47 & 201 & 210 & 16479 \\
\hline D & 143 & 43 & 115 & 179 & 12034 \\
\hline E & 65 & 30 & 68 & 97 & 4790 \\
\hline F & 104 & 25 & 83 & 138 & 12917 \\
\hline G & 74 & 18 & 70 & 90 & 6012 \\
\hline H & 71 & 21 & 65 & 85 & 7061 \\
\hline I & 97 & 29 & 115 & 131 & 7868 \\
\hline K & 91 & 36 & 85 & 144 & 11013 \\
\hline L & 27 & 12 & 29 & 64 & 1617 \\
\hline M & 110 & 14 & 49 & 65 & 2940 \\
\hline Average & 138 & 38 & 127 & 155 & 11046 \\
\hline
\end{tabular}

Table 2. Estimation of the parameters of the SFA by the maximum likelihood model

\begin{tabular}{|l|l|l|l|l|}
\hline Variables & Parameters & Coefficients & SD & t-statistics \\
\hline Constant & $\beta_{0}$ & 3.9 & 0.50 & 7.9 \\
\hline Active beds & $\beta_{1}$ & 0.87 & 0.22 & 3.9 \\
\hline Physician & $\beta_{2}$ & 0.26 & 0.18 & 1.4 \\
\hline Nursing staff & $\beta_{3}$ & -0.75 & 0.22 & 3.3 \\
\hline Others staff & $\beta_{4}$ & 0.83 & 0.25 & 3.2 \\
\hline Sigma square & $\sigma^{\overline{2}}$ & 0.42 & 0.08 & 5 \\
\hline Gamma & $\gamma$ & 0.99 & 0.01 & 97.5 \\
\hline
\end{tabular}

Log likelihood: -22.2; LR test: $15.7(\mathrm{P}<0.05)$

Table 3. Estimation of elasticity of inputs of production and types of return to scale

\begin{tabular}{|l|l|l|l|l|l|}
\hline Variables & Active beds & Physicians & Nursing staff & Other staff & Return to scale \\
\hline Parameters & $E_{Y, B}$ & $E_{Y, P}$ & $E_{Y, N}$ & $E_{Y, o}$ & RTS \\
\hline Elasticity & 0.87 & 0.26 & -0.75 & 0.83 & 1.21 \\
\hline
\end{tabular}

Table 4. Estimation of technical efficiency scores for the hospitals for 2007-2013

\begin{tabular}{|l|l|l|l|l|l|l|l|l|}
\hline Hospitals & 2007 & 2008 & 2009 & 2010 & 2011 & 2012 & 2013 & Average \\
\hline H & 0.91 & 0.96 & 0.86 & 0.90 & 0.89 & 0.91 & 0.93 & 0.91 \\
\hline F & 0.80 & 0.84 & 0.88 & 0.92 & 0.96 & 0.95 & 0.95 & 0.90 \\
\hline C & 0.84 & 0.91 & 0.89 & 0.88 & 0.80 & 0.82 & 0.85 & 0.86 \\
\hline G & 0.76 & 0.77 & 0.80 & 0.85 & 0.89 & 0.90 & 0.91 & 0.84 \\
\hline K & 0.59 & 0.63 & 0.64 & 0.85 & 0.80 & 0.83 & 0.85 & 0.74 \\
\hline A & 0.86 & 0.75 & 0.69 & 0.65 & 0.70 & 0.72 & 0.74 & 0.73 \\
\hline E & 0.61 & 0.58 & 0.64 & 0.60 & 0.64 & 0.65 & 0.70 & 0.63 \\
\hline D & 0.50 & 0.67 & 0.58 & 0.50 & 0.68 & 0.69 & 0.72 & 0.62 \\
\hline I & 0.52 & 0.55 & 0.52 & 0.49 & 0.72 & 0.71 & 0.65 & 0.59 \\
\hline B & 0.51 & 0.56 & 0.44 & 0.50 & 0.48 & 0.55 & 0.57 & 0.52 \\
\hline M & 0.30 & 0.15 & 0.14 & 0.44 & 0.61 & 0.63 & 0.68 & 0.42 \\
\hline L & 0.38 & 0.32 & 0.32 & 0.33 & 0.35 & 0.39 & 0.40 & 0.36 \\
\hline Average & 0.63 & 0.64 & 0.62 & 0.66 & 0.71 & 0.73 & 0.75 & 0.68 \\
\hline
\end{tabular}

\section{Discussion}

The results of our study indicated that the technical efficiency of the hospitals was not appropriate. The mean of technical efficiency of the hospitals affiliated with Kurdistan University of Medical Sciences over the study period was 0.67 , indicating there is $33 \%$ potential improvement without any increasing inputs or costs. This finding is consistent with the results of the study conducted in hospitals affiliated with Lorestan University of Medical Sciences (0.71) and hospitals affiliated with Kermanshah University of Medical Sciences $(0.63)(11,4)$. Based on the study 
period, the mean of technical efficiency was greater in 2013 than it was in 2007 (by about 0.12). In other words, the performance of the hospitals based on TE over the eight years of the study had a positive, upward trend. (It only declined in 2009 compared with 2008.) The increase and decrease of the trend were found in others studies (4, 7, 12). In this study, the Cobb-Douglas function was used to estimate the frontier production function, and the results showed this form, compared to the Translog functional form, was more appropriate, which was consistent with the results of a study conducted by Gannon (13). The results of our study indicated that the elasticity of active beds was greater than that of other variables, and the elasticity of nursing was negative, i.e., - 0.75 . A study conducted by Goudarzi et al. showed that the beds had the highest elasticity and that the elasticity of nursing was negative (4). The negative elasticity of nursing indicated that the number of nurses in the hospitals was more than the other inputs, such as beds, other staff, and physicians. In our study, the return to scale was increasing, which was consistent with a study conducted by Rezaei et al. in hospitals affiliated with Kurdistan University of Medical Sciences (14). The results of our study about ranked hospitals based on technical efficiency indicated that the highest and lowest mean scores were Sina Kamyaran and Shohada Dehgolan, respectively, which was consistent with the findings of a study conducted by Miraki et al. in hospitals affiliated with Kurdistan University of Medical Sciences in 2014 (15). Note that the methods used to evaluate the performance in both studies were completely different.

The current study has several limitations, so the results must be used with caution. First, we used the number of inpatient admissions to estimate the technical efficiency of the hospitals, and the case mix index was not considered. Second, the SFA model considered only outputs, and this may cause other important outputs in the hospitals not to be considered. Third, we did not consider the perspectives of the patients when the output variable including in the analysis.

\section{Conclusions}

The results of our study indicated that, although the performance of hospitals of the Kurdistan University of Medical Sciences was better than in 2013 than in 2007, the overall performance of the hospitals over the 5-year study period was not appropriate, and about $33 \%$ of the inputs variables, such as nurses and other hospital staff members was not used. However, it is suggested that managers and planners of hospitals implement and design programs based on proper timing and plan measurement in order to use resources effectively and efficiently.

\section{Acknowledgments:}

This study was supported and funded by Kurdistan University of Medical Sciences. The authors wish to thank the staffs of the educational hospitals for their participation in the study. We also thank the Research Deputy of Kurdistan University of Medical Sciences for the financial support that was provided.

\section{Conflict of Interest:}

There is no conflict of interest to be declared.

\section{Authors' contributions:}

All authors contributed to this project and article equally. All authors read and approved the final manuscript.

\section{References}

1) Yaisawarng S. Performance measurement and resource allocation. Springer. 2002; 1(2): 61-81. doi: 10.1007/978-1-4757-3592-5_4.

2) Kiadaliri AA, Jafari M, Gerdtham UG. Frontier-based techniques in measuring hospital efficiency in Iran: a systematic review and meta-regression analysis. BMC Health Serv Res. 2013; 13(1): 1-11. doi: 10.1186/1472-6963-13-312.

3) Kuntz L, Scholtes S, Vera A. Incorporating efficiency in hospital-capacity planning in Germany. Eur J Health Econ. 2007; 8: 213-23. PMID: 17216425.

4) Goudarzi R, RjabiGilan N, Ghasemi SR, Reshadat S, Askari R, Ahmadian M. Efficiency measurement using econometric stochastic frontier analysis (SFA) method, Case study: hospitals of Kermanshah University of Medical Sciences. J Kermanshah Univ Med Sci. 2014; 17(10): 666-72. Available from: http://journals.kums.ac.ir/ojs/index.php/jkums/article/view/911

5) Coelli TJ. A Guide to DEAP Version 2.1: A data envelopment analysis (computer) program. Center for Efficiency and Productivity Analysis University of New England Working paper. 1996; 96(08). Available from: http://www.owlnet.rice.edu/ econ380/DEAP.PDF 
6) Meybodi Emami A. [Principles of measuring performance and productivity: practical application (Persian)]. 2st ed Tehran: Publishing Business Studies and Research Institute. 2005: 10-5.

7) Sajadi H, Karami Mehrgan T, Karimi S, Bidram R. Efficiency Estimation in General Hospitals of Isfahan University of Medical Sciences during 2005-2006 by Data Envelopment Analysis. Journal of Health Administration. 2009; 12(36): 39-46. Available from: http://jha.iums.ac.ir/browse.php?a_code=A-10-1654\&slc_lang=en\&sid $=1$

8) Rosko MD. Cost efficiency of US hospitals: a stochastic frontier approach. Health Econ. 2001; 10(6): 53951. doi: 10.1002/hec.607, PMID: 11550294.

9) Zere E, McIntyre D, Addison T. Technical efficiency and productivity of public sector hospitals in three South African provinces. S Afr J Econ . 2001; 69(2): 336-58. doi: 10.1111/j.1813-6982.2001.tb00016.x.

10) Greene WH. Econometric Analysis. 3st ed. New York: Prentice Hall. 2005; 21-34. Available from: http://stat.smmu.edu.cn/DOWNLOAD/ebook/econometric.pdf

11) Goodarzi G, Imani MH, Jahan MN, Rostami K, Omidifar R, Mahooti F. Hospital Performance Assessment Of Lorestan University Of Medical Sciences. payesh. 2012; 11(3): 309-15. Available from: http://fa.journals.sid.ir/ViewPaper.aspx?ID=175292

12) Goodarzi G. Determinaon of technical efficiency of hospitals in Tehran University of Medical Sciences using Data Envelopment Analysis (DEA): 2000-2004. Journal of Health Management. 2007; 9(26): 31-8. Available from: http://jha.iums.ac.ir/browse.php?a_code=A-10-165-15\&slc_lang=en\&sid=1

13) Gannon B. Testing for variation in technical efficiency of hospitals in Ireland.. Econ Soc Rev. 2005; 36(3): 273. Available from: http://hdl.handle.net/2262/60845

14) Rezaei S, Miraki T, Jahanmehr N, Gharibi F. The Estimation of Production Function in Educational Hospitals of Kurdistan University of Medical Sciences (2007-2011). Hospital. 2014; 13(1): 9-16. Available from: http://jhosp.tums.ac.ir/browse.php?a_code=A-10-25-5064\&slc_lang=en\&sid=1

15) Miraki T, Rezaei S, Jahanmehr N, Mohammadi M, Gharibi F. Assessment of performance of the hospitals of Kurdistan University of Medical Sciences by use of Pabon Lasso Model (2007-2011). Scientific Journal of Kurdistan University of Medical Sciences. 2014; 19(1): 114-23. Available from: http://sjku.muk.ac.ir/browse.php?a_id=1284\&sid=1\&slc_lang=en 